\title{
Dystocia Due to Foetal Mummification in Four Goats Carrying Twin Pregnancies
}

\author{
B. Vinayak*, K. Magnus Paul, H. D. Arun, A. Raghavendra and S. Bindu \\ Department of Animal Reproduction, Gynaecology and Obstetrics \\ College of Veterinary and Animal Sciences, Mannuthy, KVASU, Kerala, India \\ *Corresponding author
}

\section{A B S T R A C T}

\section{Keywords}

Mummification, Papyraceous,

Hematic, Twin

Pregnancy,

Dystocia

Article Info

Accepted:

18 May 2020

Available Online:

10 June 2020
Dystocia reported in four goats were diagnosed with mummification of either single or twin foetuses. Mummification of foetuses was confirmed by per-vaginal examinations. One case was diagnosed as papyraceous type and other three cases were haematic type of mummification. Death of mummified foetus in one case was in third trimester whereas, in rest of the three cases it was in second trimester. Dystocia in all the four cases were due to lack of lubrication. However, both the foetuses in all four cases were delivered per-vaginally by gentle traction. All the does were medicated with fluids, antibiotics, anti-inflammatory and ecbolic drugs for five days and all four goats recovered uneventfully.

\section{Introduction}

Foetal mummification is one of the important gestational disorders of farm animals in which the exact etiology and time of foetal death are unknown (Dutt et al., 2018).

Foetal mummification is characterized by death of foetus after ossification followed by resorption of foetal fluids, foetus becomes dry and paper like (Jackson, 2004), corpus luteum remains intact and cervix remains closed. Among domestic animals, mummification is common in polytocus animals like sows, bitches and queen (Lefebvre et al., 2009). Whereas, in small ruminants this condition is uncommon and affects both single and twin foetuses.

In small ruminants, this condition is associated with toxoplasmosis, Chlamydophila, border disease, and Coxiella infection (Edmondson et al., 2012). The present paper describes dystocia due to foetal mummification in four goats carrying twin pregnancy. 


\section{Case history and clinical observation}

\section{Case 1}

A three years old full term pregnant Malabari goat weighing $28 \mathrm{~kg}$ was presented to University Veterinary Hospital, Kokkalai, KVASU, Kerala, with a complaint of reduced appetite and straining for last 12 hours. On examination, goat was dull with distended abdomen and serosanguineous vulval discharge noticed (Fig. 1). Rectal temperature was $102.5^{\circ} \mathrm{F}$ and normal mucous membrane. Right flank area was shaved and ultrasonographic examination suggested, dead foetus with reduced fluid. Perineal region of the goat was scrubbed with 1 per cent potassium permanganate solution. Per-vaginal examination revealed a firm immobile mass which was mummified engaged in the birth canal. Eyeball was lacking in mummified foetus.

\section{Case 2}

A four year old Malabari goat with history of breeding three months back, was presented to Teaching Veterinary Clinical Complex (TVCC), Mannuthy with a complaint of anorexia, straining and abnormal vaginal discharge from 24 hours. Upon abdominal palpation, a small foetal mass felt at caudal abdomen. Vulva was moist and per-vaginal examination revealed, brownish discharge and two mummified foetuses.

\section{Case 3}

A crossbred Malabari doe aged around 4 years was presented to TVCC, Mannuthy, with reduced feed and water intake, straining, oedematous and hyperaemic vulva. Breeding History was unknown. Per-vaginal examination revealed brownish exudates and presence of two mummified masses.

\section{Case 4}

A Three year old non-descriptive goat was attended at owner's door step in Kozhukully village of Thrissur district Kerala. Owner complained that goat straining with brownish exudates, anorexia and restlessness for 10 hours. Breeding history was unknown and previous kidding was normal. Perineal region of the doe was soiled it was scrubbed with luke warm water. With proper lubrication using liquid paraffin, gloved hand was inserted in vaginal cavity; placental membranes and mummified foetal mass felt. Eyeballs were lacking in the both foetuses.

\section{Diagnosis and treatment}

Diagnoses of cases were made by identifying the sticky, brownish red colour discharge from birth canal and brownish mummified foetal masses. Dystocia in all the four cases were due to lack of lubrication and fluids. First case was diagnosed as papyraceous type of mummification. In second, third and fourth cases hematic type of mummification was observed. In first case, death of mummified foetus may be in third trimester of pregnancy. Whereas, in other three cases death of foetus may be in second trimester of pregnancy.

In all the four cases, perineal region of goats was scrubbed with 1 per cent potassium permanganate solution or luke warm water. After proper lubrication of vagina using liquid paraffin, per-vaginal examination performed. Mummified foetal masses engaged in birth canal were removed with slight movement and gentle traction in all four cases (Fig. 2). In first case, only one foetus was undergone mummification and another foetus had normal growth which was a dead female (Fig. 3). In rest three cases both the foetuses were undergone mummification (Fig. 4, 5 and 6). All the four dystocia cases delivered successfully via normal vaginal delivery. 


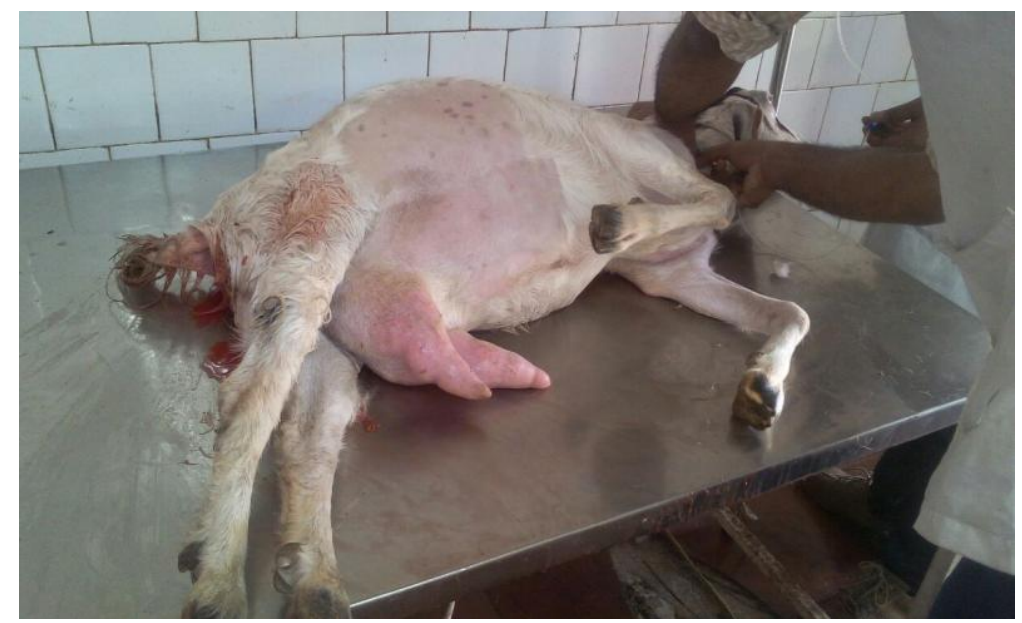

Fig.1 Distended abdomen and vulval discharge in case 1

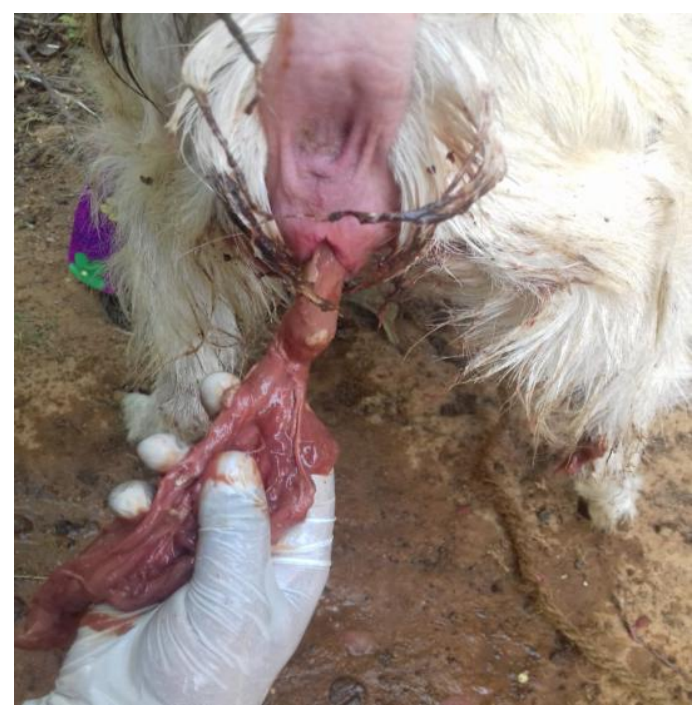

Fig.2 Lubrication of birth canal and gentle traction by gloved hands

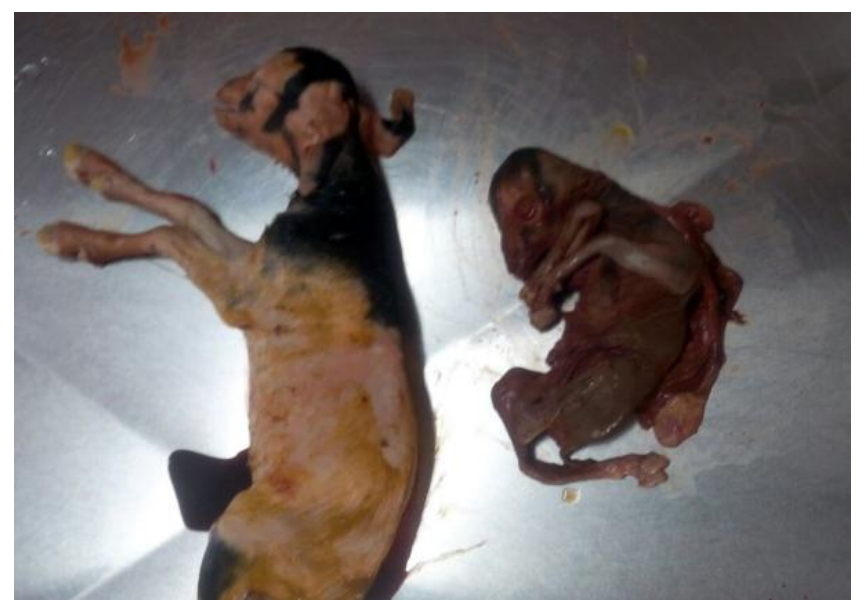

Fig.3 Case 1-One mummified and one normal foetus 


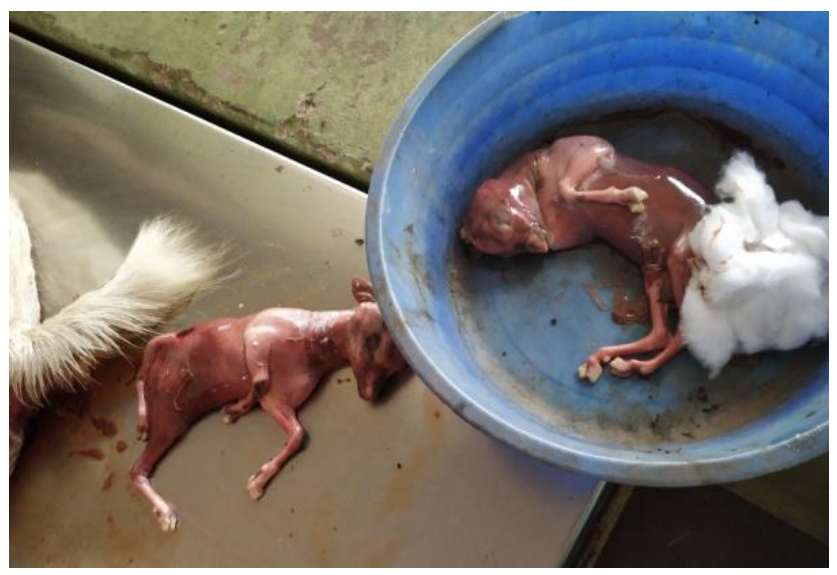

Fig.4 Case 2-Mummified twin foetuses

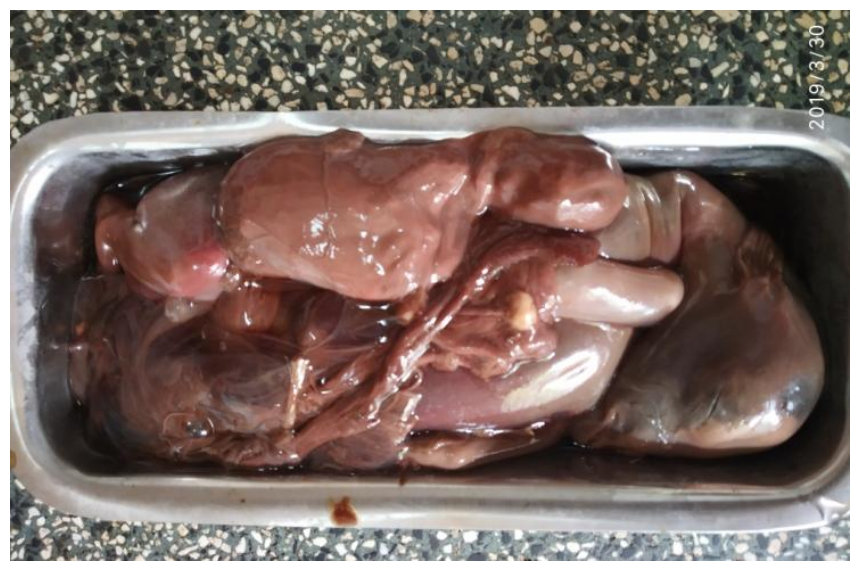

Fig.5 Case 3-Mummified twin foetuses

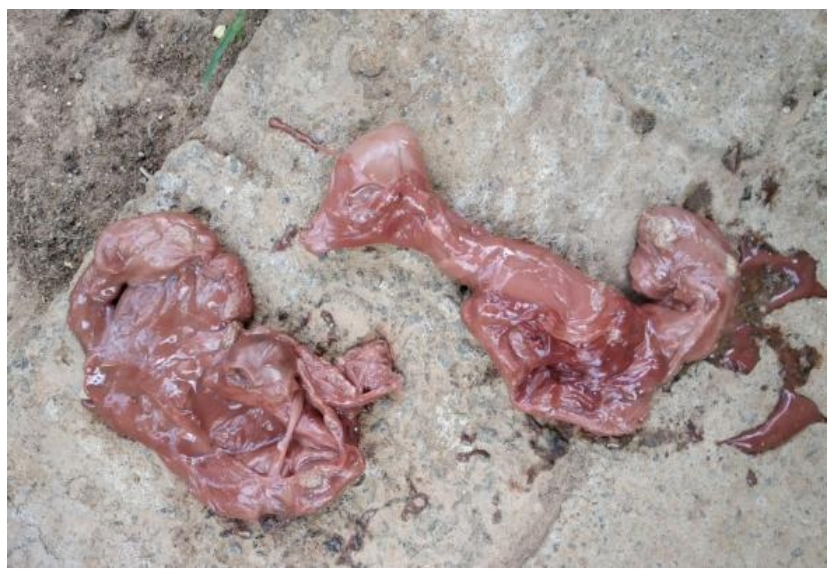

Fig.6 Case 4-Mummified twin foetuses

All the goats were administered with intravenous supportive fluid therapy, antibiotics, anti-inflammatory drugs for five days and prescribed Utrovet ${ }^{\circledR}$ bolus (Indigenous herbal uterine cleanser and ecbolic bolus). All animals recovered from the condition, with normal physiological parameters and appetite and absence of discharge from birth canal 
after three to five days of treatment. Foetal mummification is common in large litter carrying animals like swine, dogs, and cats which results in uterine overcrowding and placental insufficiency (Long, 2009). It also reported in other domestic species like cow (Moore, A.A. \& Richardson, G.F. 1995), sheep (Alagar et al., 2017), goat (Tutt, 1991, Anil et al., 2017), horse (Threlfall, 2005), pig (Christianson, 1992) and in dog and cat (Johnston and Raksil, 1987). Among these highest prevalence occurring in the swine (Long, 2009). Present observations are in agreement with Tutt (1991) who reported that foetal mummification is uncommon in goats but appears to be more common in twin pregnancy.

Foetal mummification occurs when the foetus dies due to genetic defects, torsion or compression of umbilical cord, placental defects or infections during second or third trimester of gestation. Due to presence of functional Corpus Luteum (CL) and circulating progesterone, the foetus may retain in utero (Alagar et al., 2017).

After intra-uterine foetal death, amniotic and allantoic fluids absorption results in shrivelled parchment like foetal membranes resulting in papyraceous mummification or resulting in viscous chocolate coloured deposits on the foetal membranes in haematic mummification (Noakes et al., 2009). Mummification that produces a dry, stiff foeto-placental unit with no exudates is papyraceous mummification, and has been reported in dogs, cats, cattle, buffalo, and sharks.

In haematic or chocolate mummification, a viscous adhesive material covers the mummified foetus. This type has been reported in cattle, buffalo, and dogs (Lefebvre et al., 2009). In the present cases, first one was shrivelled, parchment like without exudates and stiff foeto-placental unit hence it was papyraceous type, in other three cases viscous exudates was present which were haematic type of mummification.

Mummification of one foetus doesn't affect the normal growth of co-twin foetus. Reason for the dystocia in all the cases was due to lack of lubrication. In all the cases external os of cervix was open and foetal masses were lodged in birth canal hence it became easier to relive the dystocia. All the cases in the present paper treated successfully without complications. Mummification is the sterile condition which will not affect the future reproductive performance of animals.

\section{Acknowledgement}

The authors would like to thank the TVCC and University Veterinary Hospital teaching and non-teaching staff and all students for their assistance.

\section{References}

Alagar, S., Prakash, S., Selvaraju, M., Ravikumar, K. and Manokaran, S. 2017. Papyraceous mummification leading to dystocia of a normal foetus in a Mecheri ewe. Indian Journal of Animal Reproduction, 38: 62-63.

Anil. M., Rajashri Raju, M., Solmon, G., Raju, K.G. and Reddy, C.K. 2017. Foetal mummification in non-descript doe - a case report. International Journal of Science, Environment and Technology, 6: 2335-2338.

Christianson, W.T. 1992. Still births, mummies, abortions and early embryonic death. Vet. Clin. North. Am. Swine Reprod. 8: 623-639.

Dutt, R., Dalal, J., Singh, G. and Gahalot, S.C. 2018. Management of foetal mummification/maceration through left flank caesarean section in cows study of four cases. Advances in 
Animal and Veterinary Sciences 6: 1216.

Edmondson, M.A., Roberts, J.F., Baird, A.N., Bychawski, S. and Pugh, D.G. 2012. Theriogenology of sheep and goats. In: Pugh, D.G. and Baird, A.N. editors. Sheep and Goat Medicine. 2nd edn. Maryland Heights (M.O): Elsevier Saunders 150-230.

Jackson, P.G.G. 2004. Dystocia in the Ewe. In: Handbook of Veterinary Obstetrics. 2nd ed., Saunders, London. 105-124.

Johnston, S.D. and Raksil, S. 1987. Foetal loss in the dog and cat. Vet. Clin. North. Am. Small Anim. Pract. 17: 535-554.

Lefebvre, R.C., Saint-Hilaire, E., Morin, I., Couto, G.B., Francoz, D. and Babkine, M. 2009. Retrospective case study of foetal mummification in cows that did not respond to prostaglandin F2 $\alpha$ treatment. The Canadian Veterinary Journal 50: 71-76.
Long, S. 2009. Abnormal development of the conceptus and its consequences. In: Noakes, D.E., Parkinson, T.J. and England, G.C.W (Eds.) Veterinary Reproduction and Obstetrics (9th Edn.) W.B. Saunders Company Ltd., London.

Moore, A.A. \& Richardson, G.F. 1995. Uterine torsion and foetal mummification in a cow. Canadian vet. J. 36(11): 705-706.

Noakes, D.E., Parkinson, T.J. and England, G.C.W. 2009. Veterinary reproduction and obstetrics (9th Edn.) W.B. Saunders Company Ltd., London.

Threlfall, W.R. 2005. Singleton mummified foetus in a standard bred mare". Equine Veterinary Education 17: 235239.

Tutt, C.L.C. 1991. Post-partum mummification of a co-twin foetus in a Cameroon Dwarf doe. Veterinary Record. 40: 229-231.

\section{How to cite this article:}

Vinayak. B., K. Magnus Paul, H. D. Arun, A. Raghavendra and Bindu. S. 2020. Dystocia Due to Foetal Mummification in Four Goats Carrying Twin Pregnancies. Int.J.Curr.Microbiol.App.Sci. 9(06): 1733-1738. doi: https://doi.org/10.20546/ijcmas.2020.906.215 